\begin{tabular}{l|l|l|c|c|}
\hline $\begin{array}{l}\text { Journal of } \\
\text { Endocrinology }\end{array}$ & H M Eggink, & $\begin{array}{l}\text { Chronic i.c.v. infusion of tLCA } \\
\text { in mice }\end{array}$ & $\mathbf{2 3 6 : 2}$ & $\mathbf{8 5 - 9 7}$ \\
\hline
\end{tabular}

RESEARCH

\title{
Chronic infusion of taurolithocholate into the brain increases fat oxidation in mice
}

\author{
Hannah M Eggink1,2,*, Lauren L Tambyrajah3,4,*, Rosa van den Berg3,4, Isabel M Mol3,4, Jose K van den Heuvel3,4, \\ Martijn Koehorst5, Albert K Groen 5,6 , Anita Boelen', Andries Kalsbeek ${ }^{1,2}$, Johannes A Romijn7, \\ Patrick C N Rensen ${ }^{3,4}$, Sander Kooijman ${ }^{3,4}$ and Maarten R Soeters 1 \\ 1Department of Endocrinology and Metabolism, Academic Medical Centre, University of Amsterdam, Amsterdam, The Netherlands \\ ${ }^{2}$ Hypothalamic Integration Mechanisms, Netherlands Institute for Neuroscience, Amsterdam, The Netherlands \\ ${ }^{3}$ Division of Endocrinology, Department of Medicine, Leiden University Medical Centre, Leiden, The Netherlands \\ ${ }^{4}$ Einthoven Laboratory for Experimental Vascular Medicine, Leiden University Medical Centre, Leiden, The Netherlands \\ 5Department of Pediatrics and Laboratory Medicine, University Medical Centre Groningen, University of Groningen, Groningen, The Netherlands \\ ${ }^{6}$ Department of Vascular Medicine, Amsterdam Diabetes Centre, Academic Medical Centre, University of Amsterdam, Amsterdam, The Netherlands \\ 7Department of Medicine, Academic Medical Centre, University of Amsterdam, Amsterdam, The Netherlands
}

Correspondence should be addressed to M R Soeters: m.r.soeters@amc.uva.nl

*(H M Eggink and L L Tambyrajah contributed equally to this work)

\section{Abstract}

Bile acids can function in the postprandial state as circulating signaling molecules in the regulation of glucose and lipid metabolism via the transmembrane receptor TGR5 and nuclear receptor FXR. Both receptors are present in the central nervous system, but their function in the brain is unclear. Therefore, we investigated the effects of intracerebroventricular (i.c.v.) administration of taurolithocholate (tLCA), a strong TGR5 agonist, and GW4064, a synthetic FXR agonist, on energy metabolism. We determined the effects of chronic i.c.v. infusion of tLCA, GW4064, or vehicle on energy expenditure, body weight and composition as well as tissue specific fatty acid uptake in mice equipped with osmotic minipumps. We found that i.c.v. administration of tLCA (final concentration in cerebrospinal fluid: $1 \mu \mathrm{M}$ ) increased fat oxidation (tLCA group: $0.083 \pm 0.006$ vs control group: $0.036 \pm 0.023 \mathrm{kcal} / \mathrm{h}, F=5.46, P=0.04$ ) and decreased fat mass (after 9 days of tLCA infusion: $1.35 \pm 0.13$ vs controls: $1.96 \pm 0.23 \mathrm{~g}, P=0.03$ ). These changes were associated with enhanced uptake of triglyceride-derived fatty acids by brown adipose tissue and with browning of subcutaneous white adipose tissue. I.c.v. administration of GW4064 (final concentration in cerebrospinal fluid: $10 \mu \mathrm{M}$ ) did not affect energy metabolism, body composition nor bile acid levels, negating a role of FXR in the central nervous system in metabolic control. In conclusion, bile acids such as tLCA may exert metabolic effects on fat metabolism via the brain.

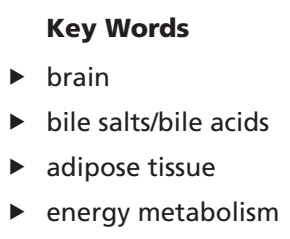

Journal of Endocrinology (2018) 236, 85-97

\section{Introduction}

Bile acids (BAs) are intestinal emulgators, but also serve as circulating signaling molecules in various organs including liver, muscle and adipose tissue (Kuipers et al. 2014).
Modulation of metabolic transcriptional programs and signaling cascades by BAs are mediated by the Takeda G protein-coupled receptor 5 (TGR5) and 
nuclear farnesoid X receptor (FXR), which are widely expressed throughout the body in rodents and humans (Parks et al. 1999, Makishima et al. 2002, Maruyama et al. 2002, Kawamata et al. 2003, Keitel et al.2010). Activation of TGR5 in intestinal L cells and pancreas induces glucagonlike peptide (GLP) 1 and insulin secretion, respectively (Thomas et al. 2009, Kumar et al. 2012). In brown adipose tissue (BAT), TGR5 increases energy expenditure by promoting thyroid hormone signaling (Watanabe et al. 2006). One of the main functions of FXR is to provide negative feedback for de novo BA synthesis in the liver (Lefebvre et al. 2009, Kuipers et al. 2014), but FXR has also been implicated in the regulation of metabolic processes outside of the enterohepatic circulation including pancreatic insulin secretion and adipocyte differentiation (Al-Shukaili et al. 2006, Rizzo et al. 2006, Abdelkarim et al . 2010). Hence, bile acids and their receptors may play an important role in the postprandial state facilitating nutrient trafficking and anabolic responses (Trauner et al. 2010, van Nierop et al. 2017).

Interestingly, BAs and these two receptors are also present in the central nervous system (Mano et al. 2004a, McMillin et al. 2016, Zheng et al. 2016). More specifically, TGR5 protein was detected in neurons and glia cells in rat and human brains using immunohistochemistry (Keitel et al. 2010) and FXR was present and active in mouse brain (Huang et al. 2016). The presence of these receptors and their agonists suggest a functional role for BAs in the brain. Considering the well-described effects of BAs in lipid and carbohydrate metabolism, we hypothesized that central effects of BA contribute to the regulation of energy metabolism.

Therefore, the aim of the present study was to determine the effects of central bile acid signaling on energy metabolism and/or BA biosynthesis in mice. We used the secondary bile acid taurolithocholate (tLCA) to modulate bile acid receptors, in particular to target TGR5. TLCA is the strongest natural TGR5 agonist (Sato et al. 2008). We used the synthetic FXR agonist GW4064 to target the FXR receptor. We show that central tLCA infusion enhances fat oxidation and results in lower fat mass in mice.

\section{Materials and methods}

\section{Animals}

Male C57Bl/6J mice (Charles River) were housed under a $12 \mathrm{~h} / 12 \mathrm{~h} \mathrm{light/darkness} \mathrm{cycle} \mathrm{in} \mathrm{temperature}\left(21-22^{\circ} \mathrm{C}\right)$ and humidity controlled rooms. Standard chow or high fat diet (HFD, energetic content: $45 \%$ fat, 35\% carbohydrates, 20\% protein) (D12451, Research Diet Services, Wijk bij Duurstede, The Netherlands) and water were available ad libitum two weeks prior and during the study. The animal protocol was approved by the Institutional Ethics Committee for Animal Procedures, Leiden University Medical Center, The Netherlands. The following experiments were carried out: Mice (15 weeks old) received chronic intracerebroventricular (i.c.v.) administration of the natural bile acid and TGR5 agonist tLCA (sodium taurolithocholate, Sigma Aldrich) or vehicle (control group). This experiment was repeated with mice on a HFD. In another experiment mice received i.c.v. administration of the synthetic FXR agonist GW4064 (Sigma Aldrich) or vehicle (control group). In an additional experiment, mice received the same dose of tLCA or vehicle intraperitoneally (i.p.) via an osmotic minipump to control for systemic effects of the compounds in the i.c.v. experiment. Final group sizes were $n=5-7$ for experiments on chow diet and $n=9-10$ for experiments on HFD.

\section{Surgery and treatment}

Mice were randomised based on body weight, anaesthetised using a mixture of dexmedetomidine $(0.5 \mathrm{mg} / \mathrm{kg})$, midazolam (5 mg/kg), and fentanyl $(0.05 \mathrm{mg} / \mathrm{kg})$, and stereotactically equipped with a cannula (Brain Infusion Kit 3, ALZET Cupertino) targeting the left lateral ventricle of the brain $(-0.45 \mathrm{~mm}$ anteroposterior, $-1.00 \mathrm{~mm}$ lateral and $2.50 \mathrm{~mm}$ dorsoventral of bregma). The cannula was secured on the skull with glue (Loctite 454, The Netherlands) and connected via a catheter to a subcutaneously placed osmotic minipump (Model 1004, ALZET). The catheter was filled with saline to delay drug delivery by $\sim 5$ days. To reach a final concentration in cerebrospinal fluid of $10 \mu \mathrm{M}$ GW4064 or $1 \mu \mathrm{M}$ tLCA, concentrations of the compounds in the minipump were calculated assuming a total cerebrospinal fluid volume of $35 \mu \mathrm{L}$ and a refresh rate of $18 \mu \mathrm{L} / \mathrm{h}$. Vehicles were $80 \%$ dimethyl sulfoxide (DMSO)/saline for GW4064 and 20\% DMSO/saline solution for tLCA. To control for leakage into the periphery, mice received the same dose of tLCA intraperitoneally using osmotic minipumps that were placed into the abdominal cavity via a small incision in the abdominal wall. All mice received appropriate stitches. The sedation was antagonized with a mixture of antiparnezol $(2.5 \mathrm{mg} / \mathrm{kg})$, flumazenil $(0.5 \mathrm{mg} / \mathrm{kg})$, and naloxone $(1.2 \mathrm{mg} / \mathrm{kg})$ and mice received postoperative analgesics $(0.03 \mathrm{mg} / \mathrm{kg} \quad$ buprenorphine). During treatment the mice were single housed in metabolic 
cages (LabMaster System, TSE Systems, Germany/for the HFD experiment: Promethion System, Sable Systems, USA). At day 9 of treatment for chow-fed mice or day 23 of treatment for HFD-fed mice, a triglyceride clearance test was performed (see below) and the mice were killed by cervical dislocation. Various organs and tissues were collected that were immediately snap frozen, fixated in $4 \%$ formalin or prepared for counting radioactivity. The brains were frozen on dry ice and subsequently sliced to control correct placement of the i.c.v. cannula.

\section{Body composition and indirect calorimetry}

Body composition was determined in conscious mice using an EchoMRI-100 (EchoMRI, Houston, TX, USA). The metabolic cages allowed measuring food intake, oxygen $\left(\mathrm{V} \cdot \mathrm{O}_{2}\right)$ consumption, carbon dioxide $\left(\mathrm{V} \cdot \mathrm{CO}_{2}\right)$ production and ambulatory physical activity (semi quantitative by beam breaks). Based on these values, we calculated the respiratory exchange ratio (RER, the ratio of carbon dioxide produced by the body to oxygen consumed by the body), energy expenditure, carbohydrate and fat oxidation rates for the last 4 days of treatment (Van Klinken et al. 2012).

\section{Triglyceride clearance test}

We prepared an emulsion of very low density lipoprotein (VLDL)-like triglyceride-rich lipoprotein emulsion particles from $100 \mathrm{mg}$ of total lipid including glycerol trioleate (triolein; $70 \mathrm{mg}$ ), egg yolk phosphatidylcholine (22.7 mg), lysophosphatidylcholine $(2.3 \mathrm{mg})$, cholesteryl oleate $(3.0 \mathrm{mg})$ and cholesterol $(2.0 \mathrm{mg})$ and added glycerol tri $\left.{ }^{3} \mathrm{H}\right]$ oleate $\left(\left[{ }^{3} \mathrm{H}\right] \mathrm{TO}\right)(100 \mu \mathrm{Ci})$. The emulsion was sonicated and fractionated using successive density gradient ultracentrifugation steps (Rensen et al. 1997) and the fraction containing TRL-like particles with an average size of $80 \mathrm{~nm}$ was isolated. The isolated particles were stored at $4^{\circ} \mathrm{C}$ under argon and used within 5 days after preparation.

To study the uptake of triglyceride-derived fatty acids, mice were fasted for $4 \mathrm{~h}$ and blood was drawn via the tail vein to determine BA levels (for the complete protocol, Supplementary methods, see section on supplementary data given at the end of this article). Subsequently, at $t=0$, the mice received an iv injection of the prepared $\left[{ }^{3} \mathrm{H}\right]$ TO-labeled VLDL-like emulsion particles (1 mg TG). After $15 \mathrm{~min}$, mice were killed and perfused with ice-cold saline. We calculated the uptake of $\left[{ }^{3} \mathrm{H}\right] \mathrm{TO}$-derived radioactivity by metabolic organs and expressed it as a percentage of injected dose per gram wet tissue weight.

\section{Bile acid analysis}

Plasma BA concentrations were determined using liquid chromatography-tandem mass spectrometry (sample preparation and analysis are detailed in Supplementary methods). The assay included 22 different types of BAs, but not all BA types were present in murine plasma including unconjugated and conjugated forms of lithocholic acid (LCA). Therefore, total BA concentration consisted of ursodeoxycholic acid (UDCA), cholic acid (CA), chenodeoxycholic acid (CDCA), deoxycholic acid (DCA), $\beta$-muricholic acid ( $\beta$-MCA) and taurine (t) conjugated forms tCA, tDCA, $\mathrm{t} \alpha-\mathrm{MCA}$ and $\mathrm{t} \beta$-MCA. If one of these BA did not reach the lower limit of quantification (LOQ), the value was set to $50 \%$ (i.e. $0.025 \mu \mathrm{M}$ ).

\section{RNA isolation, CDNA synthesis and qPCR analysis}

RNA was isolated and purified using TRI Reagent (Ambion) and a Total RNA isolation kit (Macherey Nagel) according to the manufacturers' protocols. The RNA yield was determined with a spectrophotometer (DenoVix) and cDNA was synthesized with equal RNA input using the AMV first-strand cDNA synthesis kit with oligo $d(T)$ primers (Roche Molecular Biochemicals). We performed cDNA reactions without reverse transcriptase in order to check for genomic DNA contamination. Quantitative real-time PCR was done using the SensiFAST SYBR No-ROX kit (Bioline) and the Lightcycler 480 (Roche). Quantification was done with LinReg software. The expression value of a gene of interest was normalized to the geometric mean of three reference genes according to the Minimum Information for Publication of Quantitative Real-Time PCR Experiments guidelines. The expression of the reference genes did not significantly differ between groups. Supplementary Table 1 shows a list of primers we tested.

\section{Histological analysis of fat depots}

Subcutaneous and gonadal white adipose tissue (sWAT and gWAT, respectively) and interscapular and subscapular brown adipose tissue (iBAT and sBAT, respectively) were formalin-fixed and paraffin embedded. Five micrometer sections were sliced and stained for hematoxylin eosin (HE), tyrosine hydroxylase (TH) (Ab112, Abcam) or uncoupling protein 1 (UCP1) (Ab10983, Abcam) as described previously (Kooijman et al. 2015b). Pictures were taken using an Axioskop (Zeiss) microscope with neofluar objectives (Zeiss), MicroPublisher 5.0 RTV 
camera (Q imaging) and ImagePro Plus 6.3 software (Media Cybernetics). All images were inspected while blind for the experimental condition. We quantified WAT adipocyte size in HE-stained sections by running particle analysis in ImageJ. In BAT the percentage of area occupied with intracellular lipid vacuoles in HE-stained sections and percentage of area positive for $\mathrm{TH}$ staining or the relative intensity of UCP1 staining was determined by threshold analysis in ImageJ software.

\section{Statistics}

The main outcome parameters of this study were respiratory exchange ratio (RER), energy expenditure (EE) in kilocalories per hour $(\mathrm{kcal} / \mathrm{h})$, physical activity in number of beam breaks (bb), fat oxidation in $\mathrm{kcal} / \mathrm{h}$ and carbohydrate oxidation in $\mathrm{kcal} / \mathrm{h}$ from the metabolic cages, and the body weight and body composition in grams (g) at the end of treatment. Metabolic cage data were analysed using a repeated measures two-way ANOVA with independent variables Time and Group. Statistics are presented with $F$ (DFn, DFd) value and $P$. For other outcomes, the differences between treatment and control group were analysed using a two-tailed $t$-test. Statistics are presented with $t(d f)$ value and $P$. These data analyses were conducted using GraphPad Prism 6.0 statistical software. Mean day and night outcomes for the metabolic cages were analysed using SPSS Statistics 23 (IBM). All data are presented as mean \pm standard error of the mean (s.E.M.). Differences with $P<0.05$ were considered statistically significant, $P<0.1$ were named as trend.

\section{Results}

\section{Central tLCA infusion enhances fat oxidation and decreases fat mass}

Central chronic infusion of tLCA in mice fed a chow diet decreased respiratory exchange ratio (RER) during the dark period ( $t=2.62, P=0.03$; Fig. $1 \mathrm{~A})$ although total energy expenditure in the dark did not significantly change ( $t=-1.89, P=0.09$; Fig. 1B). This was reflected by increased overall fat oxidation rate compared to control mice ( $F=5.46, P=0.04$ ) (Fig. $1 \mathrm{C}$ ), whereas carbohydrate oxidation rate remained unaffected (Fig. 1D). This effect was more prominent during the dark phase $(t=-2.73$, $P=0.02$ ) than during the light phase. I.c.v. tLCA did not affect locomotor activity (Fig. 1E), suggesting that tLCA increases resting energy expenditure.
In line with these data, we observed that tLCA decreased body fat mass in mice by $26 \%(1.35 \pm 0.13$ vs $1.96 \pm 0.23 \mathrm{~g}$, $P=0.03)$, although this was not reflected in changes in the total body weight (Fig. 2A and Supplementary Table 2). There was no difference between the groups in dietary intake. Central administration of tLCA did not alter total or individual plasma BA concentrations, including tLCA levels (Fig. 2B). tLCA could not be detected in plasma as was to be expected since concentrations of this secondary bile acid are already low in the enterohepatic circulation. In addition, intraperitoneal administration of tLCA did not affect energy expenditure (Supplementary Fig. 1), indicating that the stimulation of fat oxidation was not due leakage of tLCA into the circulation and subsequent peripheral TGR5 signaling.

\section{Central GW4064 infusion does not affect energy expenditure}

In contrast to i.c.v. administration of tLCA, central administration of the FXR agonist GW4064 did not affect RER, energy expenditure, substrate oxidation or physical activity (Fig. 3A, B, C, D and E and Supplementary Table 3 ). This observation was supported by the lack of differences in body weight and composition between GW6064 and vehicle treated mice (Fig. 4A and Supplementary Table 2). The treatment was well tolerated and there was no effect on dietary intake. In addition, GW4064 did not alter plasma total BA concentrations or BA profile (Fig. 4B), indicating the absence of leakage of GW4064 from the cerebrospinal fluid into the circulation or regulation of hepatic BA production through central pathways.

\section{Central tLCA infusion induces browning in white adipose tissue}

Since we observed that tLCA enhanced fatty acid oxidation and reduced total fat mass, we next investigated the effects of i.c.v. administration of tLCA on adipose tissue morphology, notably sWAT and gWAT. Consistent with lower fat mass in tLCA-treated animals, we observed smaller sWAT adipocytes in these mice compared to controls (i.c.v. tLCA: $416 \pm 74 \mu \mathrm{m}^{2}$, control: $676 \pm 67 \mu \mathrm{m}^{2}$; $P=0.03$ ) (Fig. 5A). Remarkably, we identified regions of subcutaneous adipocytes containing multilocular lipid droplets in five out of seven mice treated with tLCA but not in controls, hinting towards browning of sWAT (Fig. 5B). Indeed, immunohistochemical staining 


\begin{tabular}{l|l|l|l|l|} 
Journal of & H M Eggink, & Chronic i.c.v. infusion of tLCA & $\mathbf{2 3 6 : 2}$ & $\mathbf{8 9}$ \\
Endocrinology & L L Tambyrajah et al. & in mice &
\end{tabular}
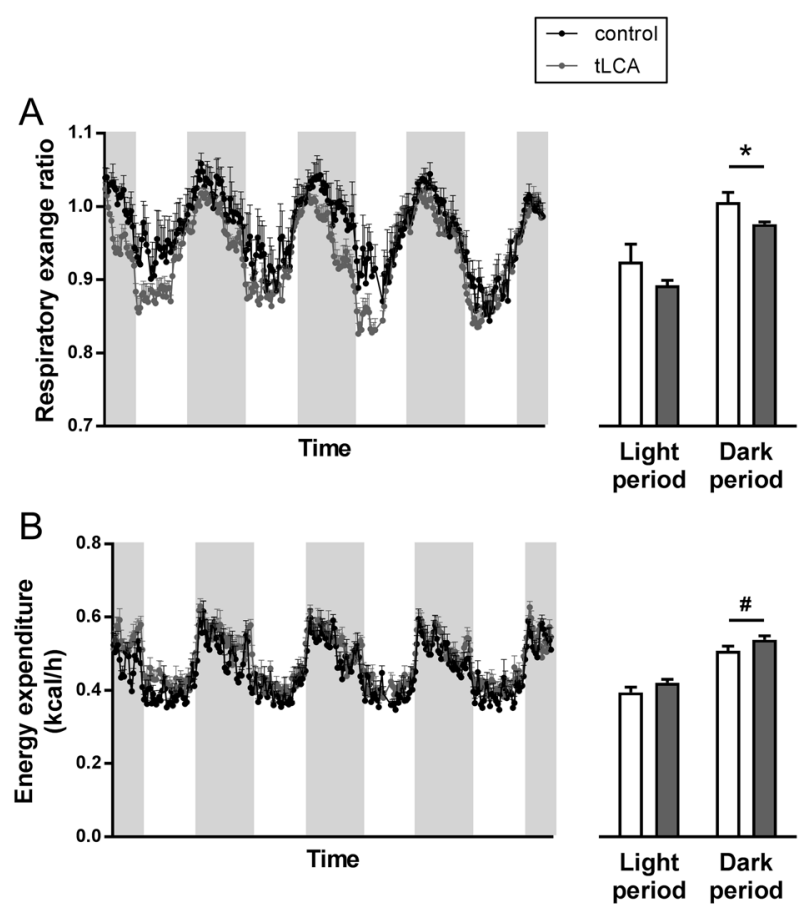

\begin{tabular}{ll|}
$\square$ & control \\
\hline & tLCA
\end{tabular}
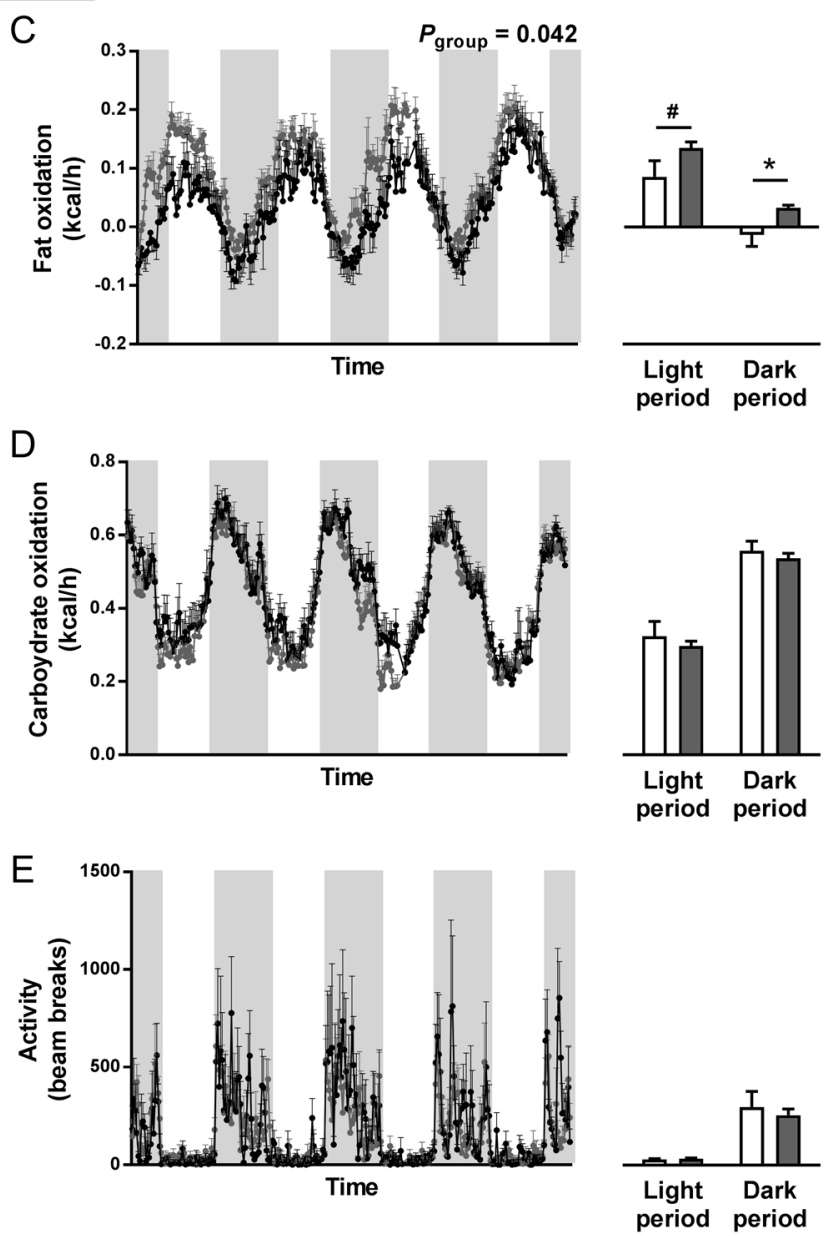

Figure 1

Calorimetrics during central tLCA administration. Mice received intracerebroventricular (i.c.v.) infusion of taurolithocholic acid (tLCA, grey) or vehicle (control) for 8 days. (A, B, C, D and E) Calometric outcomes of the metabolic cages of the last 4 days (grey background: lights off/darkness period) and mean of the light and darkness period. (A) Respiratory exchange ratio (RER), the animals that received i.c.v. tLCA had significantly lower RER during the darkness period. (B) Energy expenditure (EE), during the darkness period EE tended to be increased in i.c.v. tLCA mice. (C) Fat oxidation, mice that received i.c.v. tLCA showed overall significantly increased fat oxidation rates compared to vehicle treated controls. This effect was most pronounced during the darkness period. (D) Carbohydrate oxidation. (E) Physical activity. Data are presented as mean \pm S.E.M., ${ }^{*} P<0.05,{ }^{\#} P<0.1$.

confirmed the presence of uncoupling protein 1 (UCP1) within these regions (Fig. 5C) and increased presence of tyrosine hydroxylase $(\mathrm{TH})$, which is the rate-limiting enzyme in norepinephrine production (Fig. 5D). No effects of i.c.v. infusion of tLCA on the hypothalamicpituitary-thyroid (HPT) axis were found as determined by TSHb mRNA expression in the pituitary (Bianco et al. 2014) (not shown). Together, these data suggest enhanced sympathetic signaling toward sWAT. TLCA treatment did not alter mRNA expression of thermogenic genes including Ucp1, Pgc1a, Fas, Fxr and Hsl in whole tissue gene expression analysis of sWAT (Fig. 5E). However, it must be noted that the mice that showed browning of the sWAT had the highest Ucp1 mRNA expression. Central administration of tLCA did not alter gWAT adipocyte size (Fig. 5A) or weight, nor the uptake of triglyceride-derived fatty acids by the WAT depots (Fig. 5F). Thus, central infusion of tLCA appears to induce browning of sWAT, resulting in smaller adipocyte cell size.

\section{Brown adipose tissue analysis after i.c.v. tLCA administration}

Browning of WAT often coincides with increased BAT activity. Therefore, we performed additional analyses for two main brown adipose tissue (sBAT 

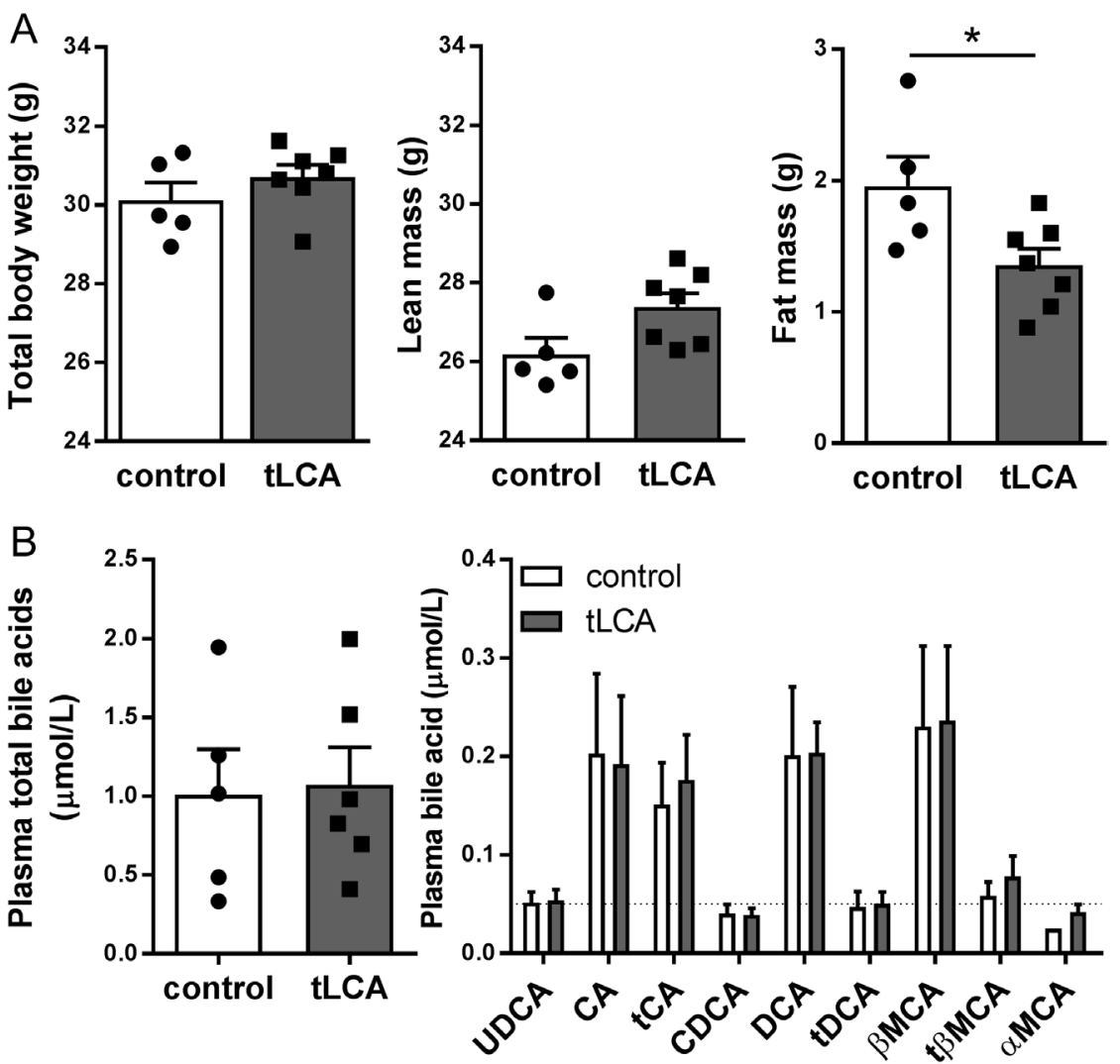

Figure 2

Body composition and plasma bile acids after chronic central tLCA administration. Mice received intracerebroventricular (i.c.v.) infusion of taurolithocholic acid (tLCA, grey) or vehicle (control) for 8 days after which body composition and plasma bile acid profile were measured. (A) There were no differences between the groups in total body weight or lean mass. However, mice that received tLCA had lower fat mass than their controls. (B) The plasma total bile acid concentration and bile acid profile did not differ between mice that received i.c.v. tLCA and their vehicle treated controls. If a bile acid was not detected, its concentration was set to $50 \%$ of the lower limit of detection (dotted line), i.e. $0.025 \mu \mathrm{M}$. UDCA, ursodeoxycholic acid; CA, cholic acid; CDCA, chenodeoxycholic acid; DCA, deoxycholic acid; MCA, muricholic acid; t-: taurine conjugated form. Data are presented as mean \pm S.E.M., ${ }^{*} P<0.05$. and iBAT) depots. I.c.v. tLCA only tended to increase the uptake of triglyceride-derived fatty acids in sBAT (i.c.v. tLCA: $27.5 \pm 5.0 \%$ dose/g, control: $12.9 \pm 4.1 \%$ dose $/ g ; P=0.06)$, but in iBAT there was no difference between the groups (i.c.v. tLCA: $34.6 \pm 8.9 \%$ dose $/ g$, control: $15.9 \pm 5.1 \%$ dose $/ g ; P=0.12$ ), possibly related to lack of power (Fig. 6A). Histological analysis of both BAT depots revealed no significant differences between the groups in brown adipocyte lipid content (Fig. 6B). I.c.v. tLCA only tended to increase protein expression of tyrosine hydroxylase (TH) and UCP1 in iBAT, but not in sBAT (Fig. 6C and D). There were no differences between the i.c.v. tLCA group and control group in mRNA expression of genes involved in lipid oxidation and the previously reported BA-induced TGR5-D2-UCP1 pathway (Fig. 6E). Together these data seem to suggest that tLCA regulates energy expenditure through central bile acid signaling by increasing the sympathetic outflow towards the white and possibly brown fat depots, thereby enhancing the thermogenic capacity of the tissues, although it must be noted that no statistically significant effects were found in the brown adipose tissue.

\section{White and brown adipose tissue analysis in HFD-fed mice after i.c.v. tLCA administration}

Next, we investigated whether tLCA treatment can protect against the metabolic consequences of HFD feeding. Similar to lean mice on chow diet, i.c.v. administration of tLCA did not promote the uptake of triglyceride-derived fatty acids by the WAT depots (Fig. 7A). We also did not observe significant differences in sWAT mRNA expression of metabolically relevant markers between treatment groups, although again Ucp1 tended to be increased (Fig. 7B). In addition, we observed that tLCA treatment enhanced uptake of triglyceride-derived fatty acids by BAT depots (Fig. 7C). These results were accompanied by a marked increase in mRNA expression of thermogenic genes including Lpl, Tgr5, Dio2 and Ucp1, indicating increased BAT thermogenic activity (Fig. 7D).

tLCA treatment did not affect energy expenditure when mice were fed a HFD, resulting in unchanged body weight or gWAT weight (Supplementary Fig. 2). Taken together, these findings indicate that chronic central tLCA treatment is not able to overcome the metabolic consequences of HFD feeding, despite brown adipose tissue activation. 


\begin{tabular}{l|l|l|l|l|} 
Journal of & H M Eggink, & Chronic i.c.v. infusion of tLCA & $\mathbf{2 3 6 : 2}$ & $\mathbf{9 1}$ \\
Endocrinology & L L Tambyrajah et al. & in mice
\end{tabular}
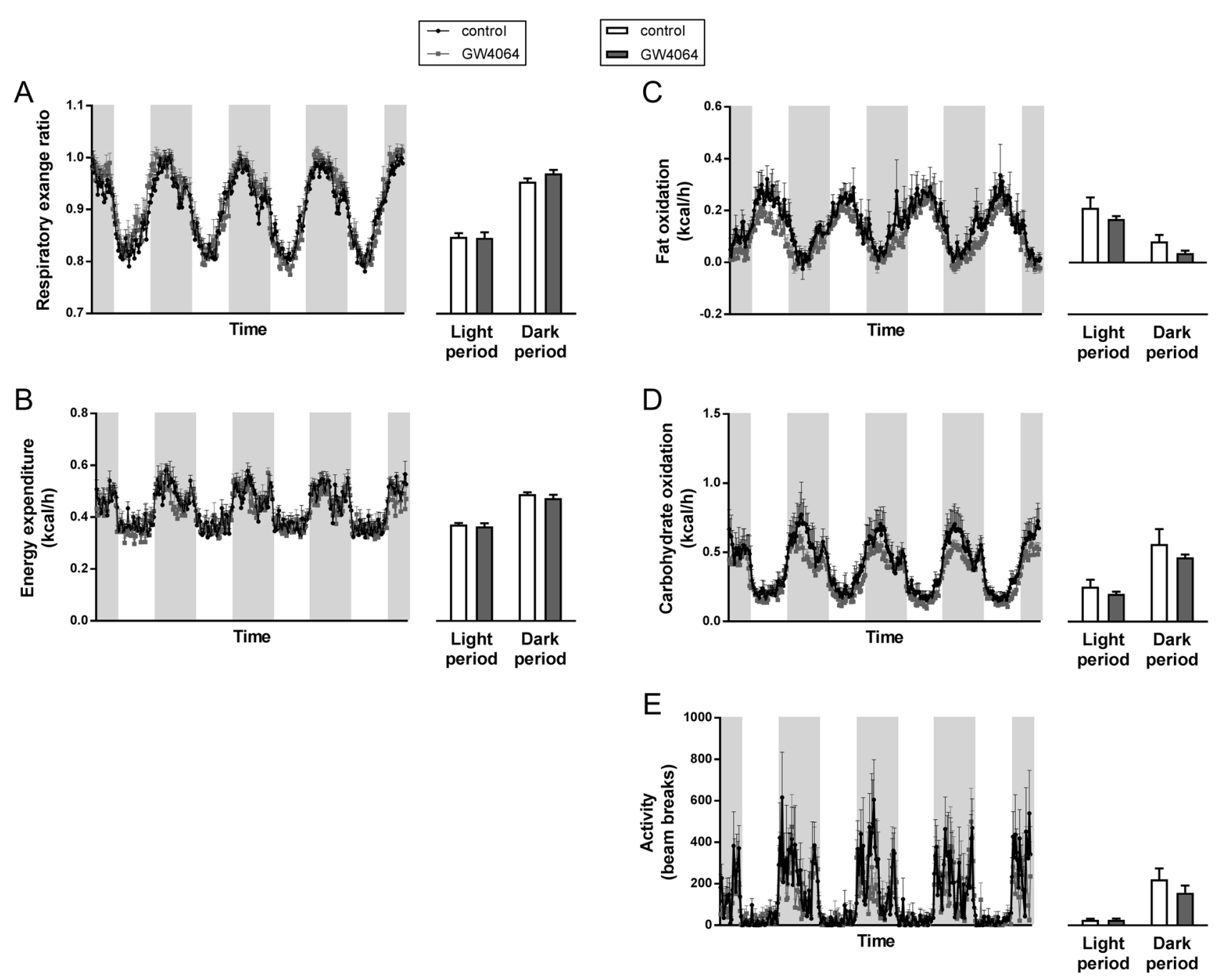

Figure 3

Calorimetrics during central FXR agonist administration. Mice received intracerebroventricular (i.c.v.) infusion of the synthetic FXR agonist GW4064 (dark grey) or vehicle (control) for 8 days. (A, B, C, D and E) Calorimetric outcomes of the metabolic cages of the last 4 days (grey background: lights off/ darkness period) and means for the light and darkness period. (A, B, C, D and E) There were no differences between the i.c.v. GW4064 and control group in (A) respiratory exchange ratio, (B) energy expenditure (control group $n=4$ ), (C) fat oxidation, (D) carbohydrate oxidation or $(E)$ physical activity. Data are presented as mean \pm S.E.M.

\section{Discussion}

In this study, we showed that chronic central infusion of the bile acid tLCA in chow fed mice increases fat oxidation and reduces fat mass associated with increased browning of subcutaneous white adipose tissue (sWAT). These effects of i.c.v. administration of tLCA are not explained by leakage of tLCA into the systemic circulation, since infusion of the same dose of tLCA into the peritoneal cavity did not influence metabolic parameters. Central infusion of the synthetic FXR agonist, GW4064, did not influence any of the metabolic parameters, indicating that the effects of i.c.v. administration of tLCA are not explained by activation of FXR.

\begin{tabular}{|lr}
\hline http://joe.endocrinology-journals.org & ○ 2018 Society for Endocrinology \\
https://doi.org/10.1530/JOE-17-0503 & Published by Bioscientifica Ltd. \\
Printed in Great Britain
\end{tabular}

\section{Chronic İ.c.v. infusion of tLCA reduces adiposity}

Chronic central infusion of tLCA increased fat oxidation and lowered fat mass, but did not affect body weight. Most likely a longer treatment period will be needed for these metabolic changes to translate in changes in body weight. The sWAT of mice that received i.c.v. tLCA administration, showed characteristics of beige/brite fat such as multilocular lipid droplets and UCP1 expression. The beige/brite adipocytes are an intermediate form of brown and white adipocytes, and possess the capacity to dissipate stored energy in the form of heat (Harms \& Seale 2013, Rosenwald \& Wolfrum 2014). Thereby, induction of browning can increase energy expenditure. 

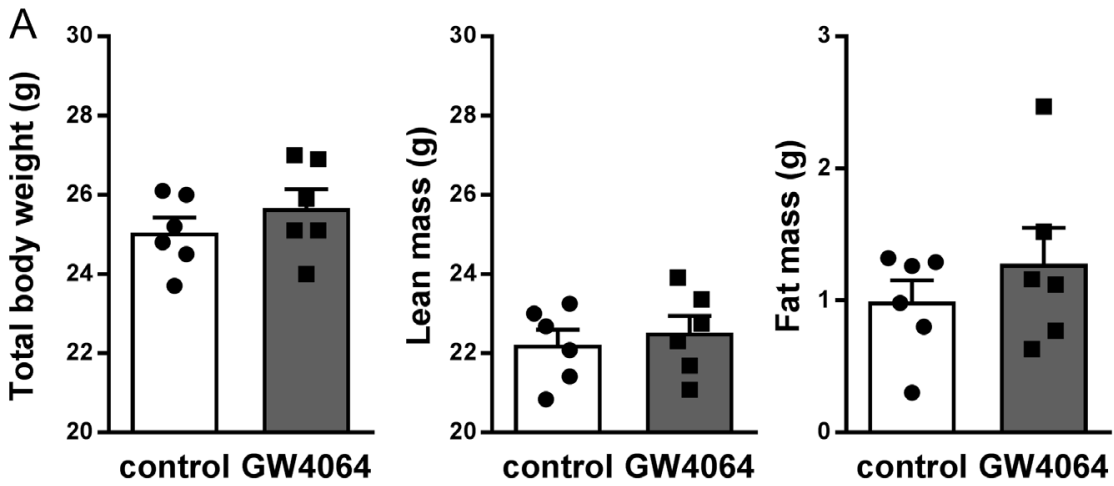

\section{Figure 4}

Body composition and plasma bile acids after chronic central FXR agonist administration. Mice received intracerebroventricular (i.c.v.)
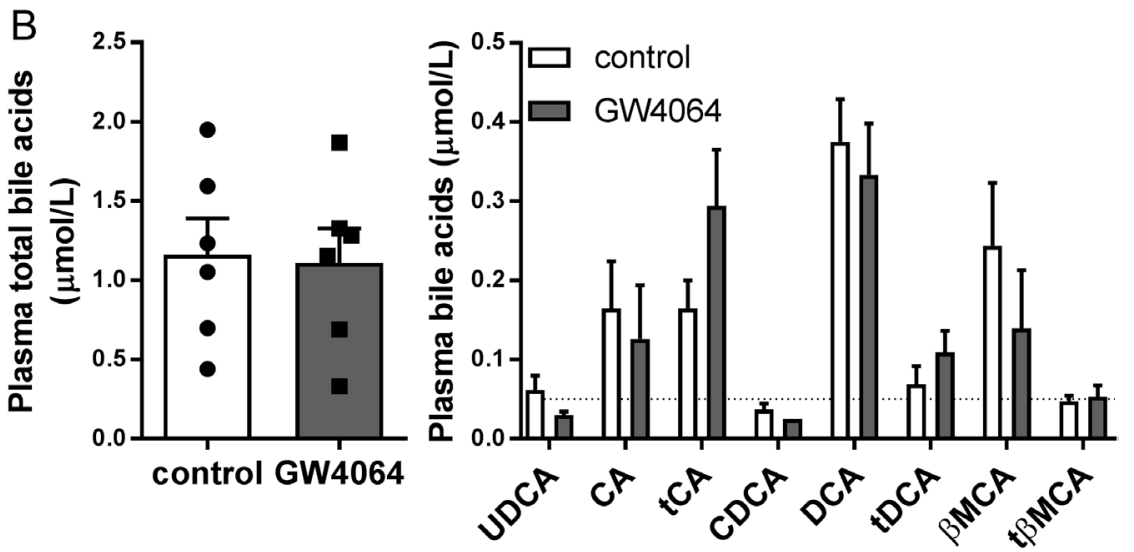
infusion of the synthetic FXR agonist GW4064 (dark grey) or vehicle (control) for 8 days after which body composition and plasma bile acid profile were measured. (A) There were no differences between the groups in total body weight, lean mass or fat mass. (B) The plasma total bile acid concentration and bile acid profile did not differ between mice that received i.c.v. GW4064 and their vehicle treated controls. If a bile acid was not detected, its concentration was set to $50 \%$ of the lower limit of detection (dotted line), i.e. $0.025 \mu \mathrm{M}$. UDCA, ursodeoxycholic acid; $C A$, cholic acid; CDCA, chenodeoxycholic acid; $D C A$, deoxycholic acid; $\beta M C A, \beta$-muricholic acid; $\mathrm{t}$-, taurine conjugated form. Data are presented as mean \pm S.E.M.

Since browning in WAT is stimulated by increased sympathetic outflow as demonstrated upon cold exposure or $\beta 3$-adrenergic receptor agonism (Berbee et al. 2015), we measured neural input to adipose tissue using TH staining. Indeed, we found increased $\mathrm{TH}$ expression at sites of browning in sWAT. Increased sympathetic innervation of sWAT is most often preceded by stimulation of BAT depots (Nedergaard \& Cannon 2014). Despite some trends, we did not observe robust effects on BAT activity in the i.c.v. tLCA group, although this is likely due to a high biological variation. When we metabolically challenged the mice by a HFD, we observed increased activity of BAT after i.c.v. tLCA treatment. However, we could not detect characteristics of browning in sWAT of the i.c.v. tLCA group. Additionally, central tLCA administration did not promote energy expenditure. Taken together our data point to a minor role for central bile acid signaling in peripheral fat metabolism.

The mechanisms by which i.c.v. administered tLCA increased fat oxidation and lowered fat mass remain speculative. Direct peripheral effects of BAs on energy expenditure have been described in both mice (Watanabe et al. 2006) and humans (Broeders et al. 2015) and explain the interest for bile acids and their receptors in the field of obesity and T2DM (Trauner et al. 2010, Prawitt et al. 2011, van Nierop et al. 2017). However, the involvement of the central nervous system in BA signaling has not been investigated before. The most important brain region that regulates and integrates metabolic signals is the hypothalamus. There is a relation between increased sympathetic outflow due to hypothalamic activation and browning of WAT and thermogenesis in BAT (reviewed in Kooijman et al. 2015a, Contreras et al. 2016). Browning of white adipose tissue occurs after selective intestinal FXR agonism via fexaramine in diet-induced obese, but not in TGR5-/- mice (Fang et al. 2015). In that study, the BA pool shifted from a predominantly ' $\mathrm{t} \beta$-MCA and $\mathrm{tCA}^{\prime}$ pool towards a ' $\mathrm{t} \beta$-MCA and $\mathrm{LCA}^{\prime}$ pool pointing at a role for TGR5 in the browning of WAT and increased thermogenic capacity. Remarkably, the contribution of LCA to the BA pool increased $\sim 4$ fold whereas total BA levels decreased. Our results suggest than central LCA signaling may have contributed to these results.

\section{Central FXR does not affect bile acid or energy metabolism}

Central infusion of GW4064, a synthetic and specific agonist of the nuclear hormone bile acid receptor FXR, did not affect energy metabolism. The main function of FXR 


\begin{tabular}{l|l|l|l|l|} 
Journal of & H M Eggink, & $\begin{array}{l}\text { Chronic i.c.v. infusion of tLCA } \\
\text { in mice }\end{array}$ & $\mathbf{2 3 6 : 2}$ & $\mathbf{9 3}$ \\
Endocrinology & L L Tambyrajah et al. &
\end{tabular}

A

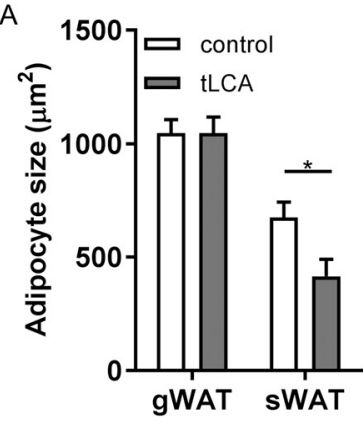

C

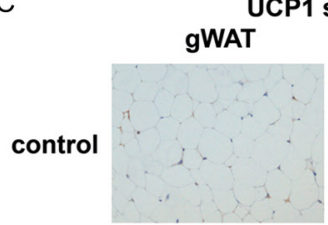

tLCA

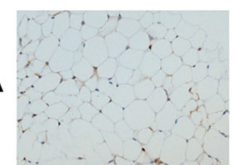

B

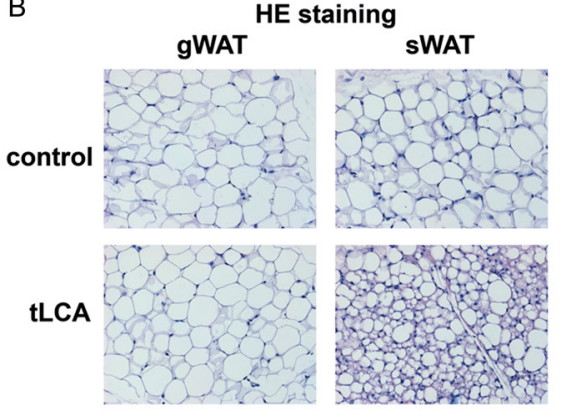

SWAT

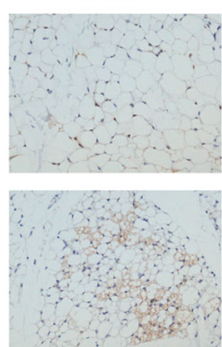

D

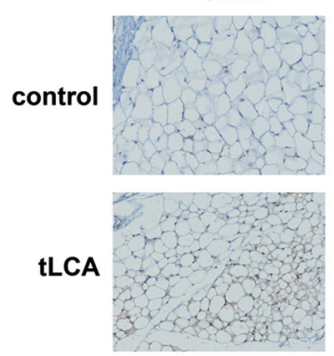

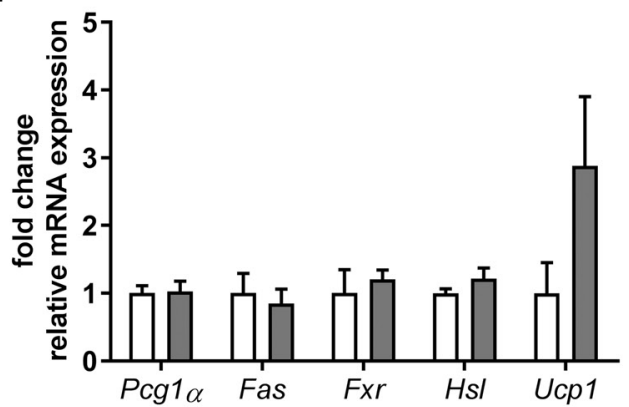

F

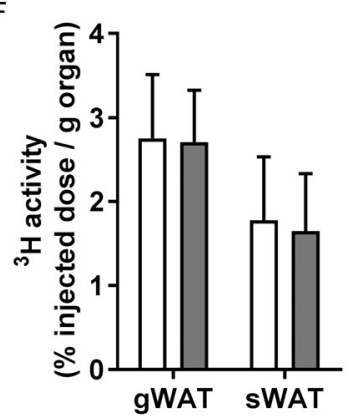

Figure 5

Changes in white adipose tissue after central tLCA administration. Mice received intracerebroventricular (i.c.v.) infusion of taurolithocholic acid (tLCA, grey) or vehicle (control, white) for 8 days. At the end of treatment, mice were injected intravenously with [ $\left.{ }^{3} \mathrm{H}\right] \mathrm{TO}-\mathrm{labeled}$ VLDL-like emulsion particles and were killed for analysis of two white adipose tissue (WAT) depots: gonadal WAT (gWAT) and subcutaneous WAT (sWAT). (A) I.c.v. tLCAtreated mice had significantly smaller adipocytes in sWAT compared to their controls. (B) Hematoxylin eosin (HE) staining showing typical examples of smaller adipocytes in sWAT of an i.c.v. tLCA-treated mouse and not in gWAT or a control mouse. (C) Immunohistochemical staining for uncoupling protein 1 (UCP1) revealed sites of browning in sWAT in the i.c.v. tLCA group and not in the control group or gWAT. (D) Also tyrosine hydroxylase (TH) expression was increased at sites of browning in sWAT. (E) mRNA expression of metabolic relevant genes in sWAT did not show significant differences between i.c.v. tLCA and control mice. However, variation in Ucp1 mRNA expression in the i.c.v. tLCA group was high and mice that showed browning of sWAT had highest Ucp1 mRNA expression. (F) There was no difference between the groups in uptake of triglyceride-derived fatty acids by gWAT or sWAT. Data are presented as mean \pm S.E.M., ${ }^{*} P<0.05$, pictures show representative examples of their group. Pcg1a, peroxisome proliferator-activated receptor gamma coactivator 1-alpha; Fas, fatty acid synthase; Fxr, farnesoid X receptor; Hsl, hormone-sensitive lipase.

in peripheral tissues is to regulate bile acid biosynthesis (Lefebvre et al. 2009). The present study did not detect a role for FXR in central metabolic control. Neither did we find any effects of chronic i.c.v. administration of a FXR agonist on plasma BA profiles or total BA concentrations. Some, but not all, studies have found FXR to be present in the brain (Huang et al. 2016, McMillin et al. 2016). Therefore, the question remains to be answered whether FXR has a functional role in the brain. We conclude that central FXR agonist administration does not influence metabolism or BA biosynthesis.

\section{Bile acids, bile acid receptors and the brain}

The role of central BAs and their receptor TGR5 is controversial. It is still unclear where BAs in the brain originate from and what their functions are (Quinn \& DeMorrow 2012). Mano and colleagues (Mano et al. 2004a) found unconjugated forms of chenodeoxycholic acid (CDCA), cholic acid (CA) and deoxycholic acid (DCA) in rat brains in a protein-bound form. Other types of BAs or unbound BAs were not detected, also not in healthy human CSF (Ogundare et al. 2010). However, many intermediates of the cholesterol-to-bile acid bioconversion have been detected in rodent brain (cells) (Zhang et al. 1997, Mano et al. 2004b) and human CSF (Ogundare et al. 2010, Saeed et al. 2014). Various enzymes are necessary for the multiple-step conversion of cholesterol into a type of bile acid. Some of these enzymes have also been detected in brain and in vitro studies demonstrated the synthesis of LCA and CDCA by brain cultures (Naqvi \& Nicholas 1970, Mano et al. 2004b). Therefore, there are indications for the presence of metabolic pathways for central BA synthesis. Another possibility is that BAs cross the bloodbrain barrier. An early study in guinea pigs demonstrated fast efflux of LCA after intracerebral injection, indicating that BAs cross the blood-brain barrier (Naqvi et al. 1970). However, more recent human studies have shown that 


\begin{tabular}{l|l|l|l|l|l} 
Journal of & H M Eggink, & $\begin{array}{l}\text { Chronic i.c.v. infusion of tLCA } \\
\text { in mice }\end{array}$ \\
Endocrinology & L L Tambyrajah et al.
\end{tabular}

control $\square$ tLCA

A
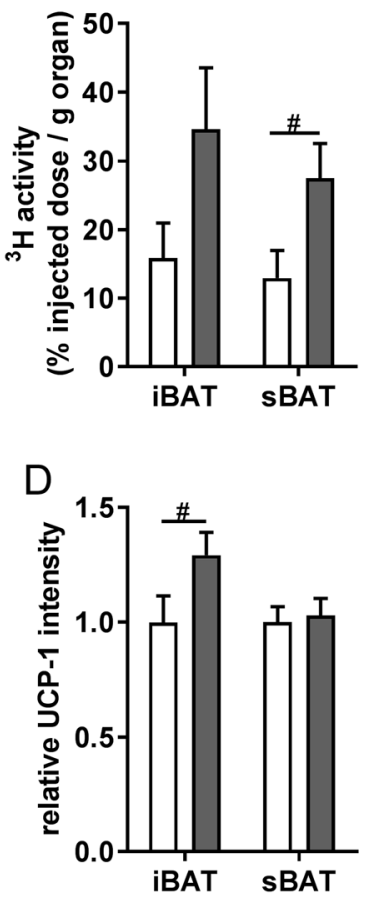

B

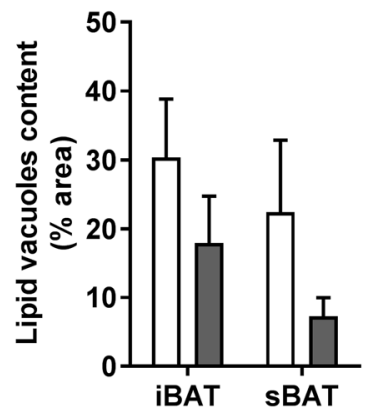

E

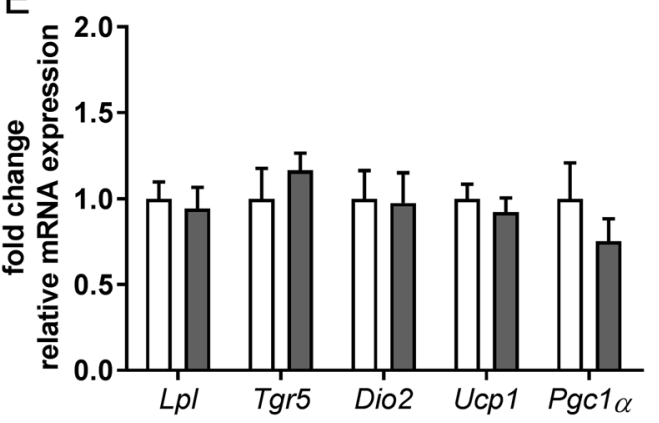

C

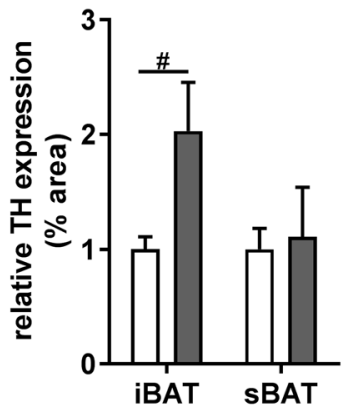

Figure 6

Changes in brown adipose tissue after central tLCA administration. Mice received intracerebroventricular (i.c.v.) infusion of taurolithocholic acid (tLCA, grey) or vehicle (control, white) for 8 days. At the end of treatment, mice were injected intravenously with [ $\left.{ }^{3} \mathrm{H}\right]$ TO-labeled VLDL-like emulsion particles and were killed for further analysis of two brown adipose tissue (BAT) depots: subscapular BAT (sBAT) and interscapular BAT (iBAT). (A) I.c.v. tLCA-treated mice showed a trend for increased triglyceride-derived fatty acids uptake in SBAT $(P=0.06)$. (B) There was no statistical difference between the groups in BAT lipid content. ( $\mathrm{C}$ and D) Immunohistochemical staining showed a trend for increased protein expression in iBAT in i.c.v. tLCA-treated mice of TH $(P=0.06)$ and UCP1 $(P=0.09)$. (E) The mRNA expression of metabolic relevant genes in SBAT was not increased. Data are presented as mean \pm S.E.M., ${ }^{\#} P<0.1$. TH, tyrosine hydroxylase; UCP1, uncoupling protein 1 ; Lpl, lipoprotein lipase; Tgr5, Takeda G proteincoupled receptor 5; Dio2, deiodinase 2; Pgc1a, peroxisome proliferator-activated receptor gamma coactivator 1-alpha.
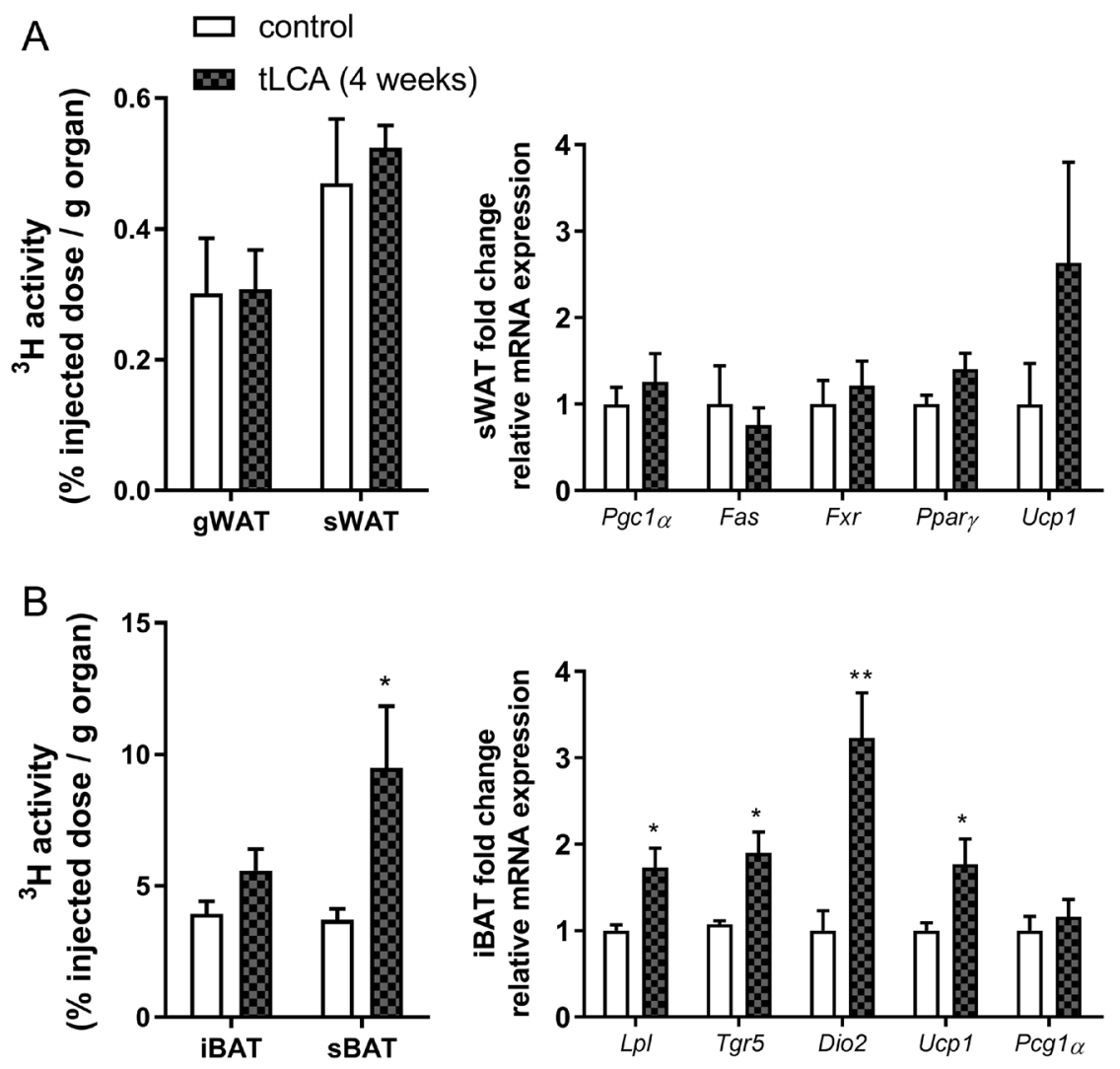

Figure 7

Changes in white and brown adipose tissue of HFD-fed mice after central tLCA administration. Mice fed a high fat diet (HFD) received intracerebroventricular (i.c.v.) infusion of taurolithocholic acid (tLCA, grey) or vehicle (control, white) for 23 days. At the end of treatment, mice were injected intravenously with [ $\left.{ }^{3} \mathrm{H}\right]$ TO-labeled VLDL-like emulsion particles and white adipose tissue (WAT) and brown adipose tissue (BAT) depots were collected for analysis. (A) Uptake of triglyceride-derived fatty acids by gonadal WAT (gWAT) and subcutaneous WAT (sWAT) did not differ between i.c.v. tLCA-treated mice and their controls. (B) Although mRNA expression of metabolically relevant markers in sWAT did not exhibit significant differences between groups, Ucp 1 expression showed a trend for increase in the i.c.v. tLCA group. (C) Uptake of triglyceride-derived fatty acids by interscapular BAT (BAT) was slightly increased and significantly increased in subscapular BAT (sBAT) in i.c.v. tLCA-treated compared to their controls.

(D) mRNA expression of metabolic relevant genes was increased in iBAT of i.c.v. tLCA-treated mice. Data are presented as mean \pm S.E.M., $* P<0.05$. $P g c 1 a$, peroxisome proliferator-activated receptor gamma coactivator 1-alpha; Fas, fatty acid synthase; Fxr, farnesoid $\mathrm{X}$ receptor; Pparg, peroxisome proliferator-activated receptorgamma; Ucp 1, uncoupling protein-1; Lpl, lipoprotein lipase; Tgr5, Takeda G proteincoupled receptor 5; Dio2, deiodinase 2 . 
BAs can in fact cross from the peripheral circulation into the brain (Parry et al. 2010). We did not detect any tLCA in plasma, therefore, we deem it unlikely that the low and slowly release dose of tLCA in our study crossed the blood brain barrier in the i.c.v. infused mice.

A limitation of our study was that we were not able to use either a very specific TGR5 agonist or a TGR5-/mouse model and this may have had two consequences. Firstly, we cannot exclude the possibility that tLCA did not stimulate FXR. However, central infusion of the FXR agonist, did not increase fat oxidation and lowers fat mass. Indeed, the affinity of tLCA for FXR is relatively low, whereas it is very high for TGR5. In a comparative activation essay Sato and coworkers showed that the $\mathrm{EC}_{50}$ of tLCA is $20 \mu \mathrm{M}$ for FXR and $0.3 \mu \mathrm{M}$ for TGR5 (Sato et al. 2008). Furthermore, tLCA is a conjugated bile acid that has lower affinity for FXR compared to true FXR agonists such as CDCA (Parks et al. 1999). Conjugated bile acids such as tLCA need active transport across the cellular membrane to activate the nuclear FXR. Although bile acid receptors, such as the apical sodium-bile acid transporter are present in the brain, their abundancy is much less compared to the ileum where active bile acid uptake occurs (Mertens et al. 2017). Finally, we are not aware of a deconjugation mechanism in the brain that may have facilitated passive uptake. All this suggests that the actions of tLCA may be mediated via TGR5 and not FXR. Secondly, tLCA may have activated other receptors than TGR5 in the brain. In vitro tLCA can interact with the muscarinic receptor M3 in Chinese hamster ovary cells, although effective concentrations were much higher than the dose we used (Raufman et al. 2002). Further investigations will be needed to dissect the function of central BAs and central TGR5, for example using a highly specific synthetic TGR5 agonist.

\section{Conclusion}

Central administration of the natural bile acid tLCA, but not a specific FXR agonist, alters peripheral fat metabolism. Therefore, central mechanisms may be involved in the metabolic effects of circulating bile acids.

\section{Supplementary data}

This is linked to the online version of the paper at https://doi.org/10.1530/ JOE-17-0503.

\section{Declaration of interest}

The authors declare that there is no conflict of interest that could be perceived as prejudicing the impartiality of the research reported.

\section{Funding}

M R S and J A R are supported by the Dutch Diabetes Research Foundation (grant 2011.80.1423). P C N R is supported by 'the Netherlands CardioVascular Research Initiative: the Dutch Heart Foundation, Dutch Federation of University Medical Centers, the Netherlands Organization for Health Research and Development and the Royal Netherlands Academy of Sciences' for the GENIUS project 'Generating the best evidence-based pharmaceutical targets for atherosclerosis' (CVON2011-19). P C N R is an Established Investigator of the Netherlands Heart Foundation (grant 2009T038).

\section{Author contribution statement}

The study was designed by $\mathrm{H} M \mathrm{M}, \mathrm{P} C \mathrm{~N}$ R and M R S. Data was acquired by $H M E, L L T, S K, M K, R \vee d B, I M M$ and J v d H. Data analysis and interpretation were performed by $H M E, L L T, S K, A K G, A B, A K, J A R$, $P C N R$ and M R S. All authors critically reviewed and have approved the final manuscript.

\section{Acknowledgments}

Thanks to C J A van der Wee-Pals (LUMC) and O V Surovtseva (AMC) for technical support.

\section{References}

Abdelkarim M, Caron S, Duhem C, Prawitt J, Dumont J, Lucas A, Bouchaert E, Briand O, Brozek J, Kuipers F, et al. 2010 The farnesoid $\mathrm{X}$ receptor regulates adipocyte differentiation and function by promoting peroxisome proliferator-activated receptor-gamma and interfering with the Wnt/beta-catenin pathways. Journal of Biological Chemistry 285 36759-36767. (https://doi.org/10.1074/jbc. M110.166231)

Al-Shukaili A, Al-Jabri AA \& Al-Moundhri MS 2006 Prognostic value of auto-antibodies in the serum of Omani patients with gastric cancer. Saudi Medical Journal 27 1873-1877.

Berbee JF, Boon MR, Khedoe PP, Bartelt A, Schlein C, Worthmann A, Kooijman S, Hoeke G, Mol IM, John C, et al. 2015 Brown fat activation reduces hypercholesterolaemia and protects from atherosclerosis development. Nature Communication 6 6356. (https:// doi.org/10.1038/ncomms7356)

Bianco AC, Anderson G, Forrest D, Galton VA, Gereben B, Kim BW, Kopp PA, Liao XH, Obregon MJ, Peeters RP, et al. 2014 American Thyroid Association Guide to investigating thyroid hormone economy and action in rodent and cell models. Thyroid 24 88-168. (https://doi.org/10.1089/thy.2013.0109)

Broeders EP, Nascimento EB, Havekes B, Brans B, Roumans KH, Tailleux A, Schaart G, Kouach M, Charton J, Deprez B, et al. 2015 The bile acid chenodeoxycholic acid increases human brown adipose tissue activity. Cell Metabolism 22 418-426. (https://doi.org/10.1016/j. cmet.2015.07.002)

Contreras C, Nogueiras R, Dieguez C, Medina-Gomez G \& Lopez M 2016 Hypothalamus and thermogenesis: heating the BAT, browning the 
WAT. Molecular and Cellular Endocrinology 438 107-115. (https://doi org/10.1016/j.mce.2016.08.002)

Fang S, Suh JM, Reilly SM, Yu E, Osborn O, Lackey D, Yoshihara E, Perino A, Jacinto S, Lukasheva Y, et al. 2015 Intestinal FXR agonism promotes adipose tissue browning and reduces obesity and insulin resistance. Nature Medicine 21 159-165. (https://doi.org/10.1038/ nm.3760)

Harms M \& Seale P 2013 Brown and beige fat: development, function and therapeutic potential. Nature Medicine 19 1252-1263. (https://doi. $\operatorname{org} / 10.1038 / \mathrm{nm} .3361)$

Huang C, Wang J, Hu W, Wang C, Lu X, Tong L, Wu F \& Zhang W 2016 Identification of functional farnesoid $\mathrm{X}$ receptors in brain neurons. FEBS Letters 590 3233-3242. (https://doi.org/10.1002/18733468.12373)

Kawamata Y, Fujii R, Hosoya M, Harada M, Yoshida H, Miwa M, Fukusumi S, Habata Y, Itoh T, Shintani Y, et al. 2003 A G proteincoupled receptor responsive to bile acids. Journal of Biological Chemistry 278 9435-9440. (https://doi.org/10.1074/jbc.M209706200)

Keitel V, Gorg B, Bidmon HJ, Zemtsova I, Spomer L, Zilles K \& Haussinger D 2010 The bile acid receptor TGR5 (Gpbar-1) acts as a neurosteroid receptor in brain. Glia 58 1794-1805. (https://doi. org/10.1002/glia.21049)

Kooijman S, van den Heuvel JK \& Rensen PC 2015a Neuronal control of brown fat activity. Trends in Endocrinology and Metabolism 26 657-668. (https://doi.org/10.1016/j.tem.2015.09.008)

Kooijman S, Wang Y, Parlevliet ET, Boon MR, Edelschaap D, Snaterse G, Pijl H, Romijn JA \& Rensen PC 2015b Central GLP-1 receptor signalling accelerates plasma clearance of triacylglycerol and glucose by activating brown adipose tissue in mice. Diabetologia $\mathbf{5 8}$ 2637-2646. (https://doi.org/10.1007/s00125-015-3727-0)

Kuipers F, Bloks VW \& Groen AK 2014 Beyond intestinal soap - bile acids in metabolic control. Nature Reviews Endocrinology 10 488-498. (https://doi.org/10.1038/nrendo.2014.60)

Kumar DP, Rajagopal S, Mahavadi S, Mirshahi F, Grider JR, Murthy KS \& Sanyal AJ 2012 Activation of transmembrane bile acid receptor TGR5 stimulates insulin secretion in pancreatic beta cells. Biochemical and Biophysical Research Communications 427 600-605. (https://doi org/10.1016/j.bbrc.2012.09.104)

Lefebvre P, Cariou B, Lien F, Kuipers F \& Staels B 2009 Role of bile acids and bile acid receptors in metabolic regulation. Physiological Reviews 89 147-191. (https://doi.org/10.1152/physrev.00010.2008)

Makishima M, Lu TT, Xie W, Whitfield GK, Domoto H, Evans RM, Haussler MR \& Mangelsdorf DJ 2002 Vitamin D receptor as an intestinal bile acid sensor. Science 296 1313-1316. (https://doi. org/10.1126/science.1070477)

Mano N, Goto T, Uchida M, Nishimura K, Ando M, Kobayashi N \& Goto J $2004 a$ Presence of protein-bound unconjugated bile acids in the cytoplasmic fraction of rat brain. Journal of Lipid Research 45 295-300. (https://doi.org/10.1194/jlr.M300369-JLR200)

Mano N, Sato Y, Nagata M, Goto T \& Goto J 2004b Bioconversion of 3beta-hydroxy-5-cholenoic acid into chenodeoxycholic acid by rat brain enzyme systems. Journal of Lipid Research 45 1741-1748. (https://doi.org/10.1194/jlr.M400157-JLR200)

Maruyama T, Miyamoto Y, Nakamura T, Tamai Y, Okada H, Sugiyama E, Nakamura T, Itadani H \& Tanaka K 2002 Identification of membranetype receptor for bile acids (M-BAR). Biochemical and Biophysical Research Communications 298 714-719. (https://doi.org/10.1016/ S0006-291X(02)02550-0)

McMillin M, Frampton G, Quinn M, Ashfaq S, de los Santos M 3rd, Grant S \& DeMorrow S 2016 Bile acid signaling is involved in the neurological decline in a murine model of acute liver failure. American Journal of Pathology 186 312-323. (https://doi.org/10.1016/j. ajpath.2015.10.005)

Mertens KL, Kalsbeek A, Soeters MR \& Eggink HM 2017 Bile acid signaling pathways from the enterohepatic circulation to the central nervous system. Frontiers in Neuroscience 11617.
Naqvi SH \& Nicholas HJ 1970 Conversion of 3-keto-5-beta-cholanoic acid to lithocholic acid by guinea pig brain tissue, in vitro. Steroids $\mathbf{1 6}$ 297-316. (https://doi.org/10.1016/S0039-128X(70)80115-5)

Naqvi SH, Herndon BL, Del Rosario L \& Nicholas HJ 1970 Intracerebrally injected monohydroxy and other C24 steroid acids as demyelinating agents in the guinea pig. Lipids 5 964-969. (https://doi.org/10.1007/ BF02533198)

Nedergaard J \& Cannon B 2014 The browning of white adipose tissue: some burning issues. Cell Metabolism 20 396-407. (https://doi. org/10.1016/j.cmet.2014.07.005)

Ogundare M, Theofilopoulos S, Lockhart A, Hall LJ, Arenas E, Sjovall J, Brenton AG, Wang Y \& Griffiths WJ 2010 Cerebrospinal fluid steroidomics: are bioactive bile acids present in brain? Journal of Biological Chemistry 285 4666-4679. (https://doi.org/10.1074/jbc M109.086678)

Parks DJ, Blanchard SG, Bledsoe RK, Chandra G, Consler TG, Kliewer SA, Stimmel JB, Willson TM, Zavacki AM, Moore DD, et al. 1999 Bile acids: natural ligands for an orphan nuclear receptor. Science $\mathbf{2 8 4}$ 1365-1368. (https://doi.org/10.1126/science.284.5418.1365)

Parry GJ, Rodrigues CM, Aranha MM, Hilbert SJ, Davey C, Kelkar P, Low WC \& Steer CJ 2010 Safety, tolerability, and cerebrospinal fluid penetration of ursodeoxycholic Acid in patients with amyotrophic lateral sclerosis. Clinical Neuropharmacology 33 17-21. (https://doi. org/10.1097/WNF.0b013e3181c47569)

Prawitt J, Caron S \& Staels B 2011 Bile acid metabolism and the pathogenesis of type 2 diabetes. Current Diabetes Reports 11 160-166. (https://doi.org/10.1007/s11892-011-0187-x)

Quinn M \& DeMorrow S 2012 Bile in de brain? A role for bile acids in the central nervous system. Journal of Cell Science and Therapy $\mathbf{3}$ e113. (https://doi.org/10.4172/2157-7013.1000e113)

Raufman JP, Chen Y, Cheng K, Compadre C, Compadre L \& Zimniak P 2002 Selective interaction of bile acids with muscarinic receptors: a case of molecular mimicry. European Journal of Pharmacology $\mathbf{4 5 7}$ 77-84. (https://doi.org/10.1016/S0014-2999(02)02690-0)

Rensen PC, Herijgers N, Netscher MH, Meskers SC, van Eck M \& van Berkel TJ 1997 Particle size determines the specificity of apolipoprotein E-containing triglyceride-rich emulsions for the LDL receptor versus hepatic remnant receptor in vivo. Journal of Lipid Research 38 1070-1084.

Rizzo G, Disante M, Mencarelli A, Renga B, Gioiello A, Pellicciari R \& Fiorucci S 2006 The farnesoid X receptor promotes adipocyte differentiation and regulates adipose cell function in vivo. Molecular Pharmacology 70 1164-1173. (https://doi.org/10.1124/ mol.106.023820)

Rosenwald M \& Wolfrum C 2014 The origin and definition of brite versus white and classical brown adipocytes. Adipocyte 3 4-9. (https://doi. org/10.4161/adip.26232)

Saeed A, Floris F, Andersson U, Pikuleva I, Lovgren-Sandblom A, Bjerke M, Paucar M, Wallin A, Svenningsson P \& Bjorkhem I 2014 7alphaHydroxy-3-oxo-4-cholestenoic acid in cerebrospinal fluid reflects the integrity of the blood-brain barrier. Journal of Lipid Research $\mathbf{5 5}$ 313-318. (https://doi.org/10.1194/jlr.P044982)

Sato H, Macchiarulo A, Thomas C, Gioiello A, Une M, Hofmann AF, Saladin R, Schoonjans K, Pellicciari R \& Auwerx J 2008 Novel potent and selective bile acid derivatives as TGR5 agonists: biological screening, structure-activity relationships, and molecular modeling studies. Journal of Medicinal Chemistry 51 1831-1841. (https://doi. org/10.1021/jm7015864)

Thomas C, Gioiello A, Noriega L, Strehle A, Oury J, Rizzo G, Macchiarulo A, Yamamoto H, Mataki C, Pruzanski M, et al. 2009 TGR5-mediated bile acid sensing controls glucose homeostasis. Cell Metabolism 10 167-177. (https://doi.org/10.1016/j. cmet.2009.08.001)

Trauner M, Claudel T, Fickert P, Moustafa T \& Wagner M 2010 Bile acids as regulators of hepatic lipid and glucose metabolism. Digestive Diseases 28 220-224. (https://doi.org/10.1159/000282091) (c) 2018 Society for Endocrinology Published by Bioscientifica Ltd. Printed in Great Britain 
Van Klinken JB, van den Berg SA, Havekes LM \& Willems Van Dijk K 2012 Estimation of activity related energy expenditure and resting metabolic rate in freely moving mice from indirect calorimetry data. PLOS ONE 7 e36162. (https://doi.org/10.1371/journal.pone.0036162) van Nierop FS, Scheltema MJ, Eggink HM, Pols TW, Sonne DP, Knop FK \& Soeters MR 2017 Clinical relevance of the bile acid receptor TGR5 in metabolism. Lancet Diabetes and Endocrinology 5 224-233. (https://doi. org/10.1016/S2213-8587(16)30155-3)

Watanabe M, Houten SM, Mataki C, Christoffolete MA, Kim BW, Sato H, Messaddeq N, Harney JW, Ezaki O, Kodama T, et al. 2006 Bile acids induce energy expenditure by promoting intracellular thyroid hormone activation. Nature 439 484-489. (https://doi.org/10.1038/nature04330)

Zhang J, Akwa Y, el-Etr M, Baulieu EE \& Sjovall J 1997 Metabolism of 27-, 25- and 24-hydroxycholesterol in rat glial cells and neurons. Biochemical Journal 322 175-184. (https://doi.org/10.1042/ bj3220175)

Zheng X, Chen T, Zhao A, Wang X, Xie G, Huang F, Liu J, Zhao Q, Wang S, Wang C, et al. 2016 The brain metabolome of male rats across the lifespan. Scientific Reports 6 24125. (https://doi.org/10.1038/ srep24125)

Received in final form 28 November 2017

Accepted 11 December 2017

Accepted Preprint published online 12 December 2017
() 2018 Society for Endocrinology Published by Bioscientifica Ltd. Printed in Great Britain 